Nils Grosch/Joachim Lucchesi/ Jürgen Schebera (Hrsg.) · Kurt Weill-Studien 
Veröffentlichungen der Kurt-Weill-Gesellschaft

Dessau, Band 1

\section{Kurt Weill-Studien}

Herausgegeben von Nils Grosch, Joachim Lucchesi und Jürgen Schebera 
Die Deutsche Bibliothek - CIP - Einheitsaufnahme

Kurt-Weill-Studien / hrsg. von Nils Grosch...

- Stuttgart : M und P, Verl. für Wiss. und Forschung, 1996

(Veröffentlichungen der Kurt-Weill-Gesellschaft Dessau ; Bd. 1)

ISBN 978-3-476-45166-8

NE: Grosch, Nils [Hrsg.]; Kurt-Weill-Gesellschaft: Veröffentlichungen der Kurt-Weill-Gesellschaft...

\section{ISBN 978-3-476-45166-8}

ISBN 978-3-476-04261-3 (eBook)

DOI 10.1007/978-3-476-04261-3

Dieses Werk ist einschließlich aller seiner Teile geschützt. Jede Verwertung außerhalb der engen Grenzen des Urheberrechtsgesetzes ist ohne Zustimmung des Verlages unzulässig und strafbar. Das gilt insbesondere für Vervielfältigungen, Übersetzungen, Mikroverfilmungen und Einspeicherung in elektronischen Systemen.

M \& P Verlag für Wissenschaft und Forschung ein Verlag der J.B. Metzlerschen Verlagsbuchhandlung und Carl Ernst Poeschel Verlag GmbH in Stuttgart

(C) 1996 Springer-Verlag GmbH Deutschland

Ursprünglich erschienen bei J.B. Metzlersche Verlagbuchhandlung und Carl Ernst Poeschel Verlag GmbH in Stuttgart 1996 


\section{Zum Geleit}

Im Februar 1992 wurden in Dessau, der Geburtsstadt des Komponisten Kurt Weill, die Kurt Weill-Gesellschaft und das Kurt Weill-Zentrum gegründet. Beide haben es sich zur Aufgabe gemacht, das Werk dieses bedeutenden Musikers unseres Jahrhunderts zu pflegen und in seiner ganzen faszinierenden Stil- und Genrebreite bekannt zu machen.

Seit 1993 findet dazu jährlich im März (Weill wurde am 2. März 1900 geboren) das Dessauer »Kurt Weill-Fest» statt. Es trägt wesentlich dazu bei, das Werk des Komponisten weit über die anhaltinische Region hinaus bekannt zu machen. Getragen wird es von der Kurt Weill-Gesellschaft und der Stadt Dessau, unterstützt vom Land Sachsen-Anhalt und zahlreichen privaten Sponsoren.

Das Kurt Weill-Zentrum möchte für Deutschland das werden, was die Kurt Weill-Foundation for Music in New York schon heute international bedeutet: Zentrum der Weill-Pflege und Weill-Forschung. Schritte auf diesem Weg sind bereits getan.

In den »Veröffentlichungen der Kurt Weill-Gesellschaft Dessau«, deren Publikation der Metzler-Poeschel Verlag dankenswerterweise übernommen hat, werden die Ergebnisse solcher Arbeit vorgestellt. Der vorliegende erste Band präsentiert Beiträge einer wissenschaftlichen Konferenz während des Kurt Weill-Festes 1995, ergänzt durch einige weitere Studien sowie durch neuaufgefundene Originaltexte Kurt Weills. Sie werden an dieser Stelle als Addenda zur Ausgabe der Gesammelten Schriften von 1990 publiziert.

Der neuen Schriftenreihe wünsche ich weite Verbreitung und gute Resonanz.

Dessau, im Frühjahr 1996

Wolfgang Laczny

Präsident der Kurt Weill-Gesellschaft 


\section{Inhalt}

\section{Tamara Levitz}

»Junge Klassizität « zwischen Fortschritt und Reaktion

Ferruccio Busoni, Philipp Jarnach und die deutsche Weill-Rezeption.... 9

\section{Gunther DiehI}

Zum Verhältnis von dramaturgischer Konzeption und kompositorischer

Gestaltung in Kurt Weills früher Oper Der Protagonist

\section{Nils Grosch}

„Notiz« zum Berliner Requiem

Aspekte seiner Entstehung und Aufführung .55

\section{Andreas Hauff}

"Du kannst in jeder Sache einen Haken finden"

Überlegungen zu Kurt Weills Bürgschaft anhand der Entstehungs-

und Aufführungsgeschichte

\section{Jürgen Schebera}

Amsterdam, 11. Oktober 1934

Einiges zur Uraufführung von Weills Sinfonie Nr.2

\section{Guy Stern}

Der Weg der Verheißung: Die Genese als via dolorosa

\section{J. Bradford Robinson}

Kurt Weills Aneignung des amerikanischen Theaterliedes

Zur Entstehungsgeschichte von Johnny's Song.

\section{Elmar Juchem}

Kein Geld für »Gold! - Finanzierung einer Broadway-

Produktion am Beispiel von Lost in the Stars.

\section{Elisabeth Schwind}

"Weill hasn't changed, I have"

Zur Ästhetik des Komponisten Marc Blitzstein 


\section{Anhang: Fünf Texte von Kurt Weill}

[Klare Kompetenzen] 194

Zu meiner Kantate Das Berliner Requiem. 195

Notiz zum Lindberghflug 196

Komponisten dirigieren vor dem Berliner Mikrophon 197

[Mit geistigen Mitteln ist nichts zu machen!] 197

[Über die Sinfonie Nr. 2] 200

Über die Autoren 201 